\title{
Uma cidade e a utopia autoritária
}

A city and the authoritarian utopia

Izaias de Souza Freire*

\begin{abstract}
Resumo
Durante o regime militar, uma cidade no Sul do Brasil foi exemplar para a utopia autoritária. Em Joinville, próspero polo industrial de Santa Catarina, a cultura política local que difundiu uma imagem de cidade sem conflitos, em que o progresso harmonizava as relações sociais, encontrou ressonância no ideal do regime de 1964. Os indícios encontrados na investigação que originou o presente artigo buscam dar visibilidade à identificação que havia entre fileiras militares e o "espírito da cidade". Foram pesquisadas fontes de jornais impressos e acervo fotográfico no arquivo público da cidade.
\end{abstract}

Palavras-chaves: Joinville; Cultura política; Cidade; Autoritarismo.

\begin{abstract}
During the military regime a city in southern of Brazil was exemplary for the authoritarian utopia. In Joinville, prosperous industrial center of Santa Catarina, the local political culture that spread an image of the city without conflicts, what progress harmonized social relations, found resonance in the ideal of 1964. The evidence found in the investigation that originated this article are intended to give visibility to identify which were among military ranks and the "spirit of the city". Newspapers sources and photographic collection in the public file of the city were surveyed.
\end{abstract}

Keywords: Joinville; Political culture; Authoritarianism.

O que aproveitamos em uma cidade não são as suas setenta e sete maravilhas, mas as respostas que dá às nossas perguntas (CALVINO, 1990, p. 44). A instigante observação do viajante de Calvino é a lúcida recomendação a quem deseja entender os enigmas que envolvem uma cidade. De tudo que uma cidade outorga ao olhar que a perscruta, são as respostas que permitem decifrá-la o que melhor de si nos oferece. Para além de seus muros, praças, prédios, casas, jardins e tudo que constitui seu patrimônio arquitetônico, a experiência social que a estrutura e os horizontes de expectativas que constrói, é certamente uma chave fundamental para compreendê-la em seu tempo.

\footnotetext{
" Mestre em História pela Universidade do Estado de Santa Catarina (UDESC). Secretaria de Educação do Estado de Santa Catarina (SEDESC).
} 
Um viajante que chegasse a Joinville-SC durante o regime militar teria diante de si uma cidade de porte médio. Situada entre a serra do mar e duas capitais do Sul do Brasil, Curitiba e Florianópolis, a primeira vista, era um centro urbano de somenos importância, embora fosse inegável que o peso de suas indústrias trouxesse-lhe alguma notoriedade. A cidade vivenciou, nesse período, um surto migratório de mão-de-obra do interior do Paraná e Santa Catarina, embora suas elites insistissem reafirmar traços de uma suposta identidade germânica hegemônica, a refletir-se no modo de viver e trabalhar de sua comunidade: um lugar caracterizado pela ordem e a disciplina, onde as pessoas dormiam e acordavam cedo para trabalhar nas fábricas (TERNES, 2010).

O percurso da investigação sobre essa cidade percorreu o olhar interessado do viajante e à medida que avançava, sedimentava uma hipótese: Joinville parecia ser a cidade da utopia autoritária do regime de 1964. E sobre isso havia que responder: como uma cidade distante dos principais centros de decisão política, que não possuía a importância de uma capital, pôde mobilizar raros afetos entre os militares? A primeira vista opaca, a questão tornar-se-ia decifrável nos indícios.

Segundo Paul Ricoeur (2007) uma cidade se dá a um só tempo, a ver e a ler. A enunciação do filósofo certamente pressupõe que toda leitura leve em conta os elementos que extrapolam o limite textual, aquilo que se inscreve nas margens. $\mathrm{O}$ paradigma indiciário da escrita da história, como assinalou Carlo Ginsburg (1990), é o que delineia o passado sob a perspectiva do residual, do detalhe, do trivial: zonas privilegiadas dos sinais.

Esta investigação seguiu o curso do que poderia indicar sinais. O principal parecia coincidir com a presença constante de autoridades do regime militar, incluindo todos os generais-presidentes que visitaram a cidade sob alguma circunstância. Embora aparentemente isso pudesse ser visto, até certo ponto, como uma trivialidade em relação a Joinville, talvez apontasse para algo a mais, embora fosse razoável relacionar a outros vestígios.

Outra pista apontava na mesma direção, parecia haver vinculação entre tais visitas dos militares com a maior fábrica metalúrgica da cidade: a Fundição Tupy.

Outro fator que possivelmente corroborasse a hipótese fosse a representação da cidade feita por suas elites, sobretudo por seu segmento hegemônico, o empresariado. Ou seja, o esforço em atribuir a Joinville uma identidade fabril caracterizada pela disciplina do trabalho, da ordem e seu equivalente, o progresso: um lugar onde não havia luta de classes, um idílio que parecia coincidir com a utopia autoritária do regime. 
Este texto, dentro dos limites que o norteia, é uma tentativa de dispor de certo modo a leitura desses sinais, não necessariamente na ordem que emergiam no manuseio dos arquivos.

\title{
A cidade e os militares
}

Ao contrário de seus antecessores, os militares impuseram e ao mesmo tempo, sofreram o distanciamento popular. Cena comum nos governos Vargas, JK e Jango, em que a forma de aparição do poder fazia-se sob o contato direto com populares, nos governos militares esse modus operandi esteve ausente. O historiador Carlos Fico atribui isso como um traço distintivo nos governos militares. Haviam os militares gestados sobre si "imagens soturnas, sombrias, sobretudo carentes de calor popular." (FICO, 1997, p. 68).

Ao que parece, em grandes centros urbanos no Brasil a recepção aos ditadores não foi à mesma que em Joinville, onde sempre se garantiu calor popular nessas recepções, sobretudo no auge do regime. Castelo Branco foi o patrono da tradicional Festa das Flores, Costa e Silva reinaugurou o hospital municipal. Em ambas as ocasiões houve recepções com populares. Médici visitou a cidade em férias (1974) na companhia da esposa e foi fotografado pela imprensa local dando autógrafos. A primeira vez que esteve na cidade havia recebido o título de cidadão honorário.

Geisel, por sua vez, era quem possuía uma curiosa aproximação com a cidade, a começar por sua biografia (descendência alemã e luterana). Esteve em Joinville diversas vezes. Em 19 de outubro de 1978, próximo ao final de seu mandato, muito provavelmente na última vez, quando inaugurou o Centro Social Urbano do Itaum, o general relembrou todas essas visitas:

\begin{abstract}
Ao longo de minha vida já estive várias vezes em Joinville. Estive em função oficial, no desempenho de meus encargos como militar; estive como presidente de empresa, relacionado com a Petrobrás; estive em férias, a passeio; estive em visita à exposição de orquídeas; estive acompanhando o Presidente Castelo Branco; já estive aqui mesmo como presidente da república num $1^{\circ}$ de maio. E hoje volto, volto como das outras vezes, sempre com muito prazer porque me acostumei há muitos anos, em reconhecer em Joinville uma cidade que trabalha, uma cidade que vibra e luta diariamente para progredir e se desenvolver, onde não há ociosidade. (ARQUIVO HISTÓRICO DE JOINVILLE, 1978, p. 1). ${ }^{1}$
\end{abstract}

\footnotetext{
${ }^{1}$ ARQUIVO HISTÓRICO DE JOINVILLE. Jornais. Geisel inaugura o Centro Social Urbano no Itaum. A Notícia, $2^{\circ}$ Caderno, Joinville, 20 de out. 1978, p. 1.
} 
De todas as visitas, nenhuma foi tão notória quanto às festividades do $1^{\circ}$ de maio de 1975. Joinville tornou-se vitrine nacional. Na cidade, o governo Geisel deu visibilidade ao termômetro da distensão, após ter anunciado, no ano anterior, a abertura lenta, gradual e segura. A primeira aproximação com o operariado durante a abertura política se deu em Joinville, onde foi preparada expressiva recepção local com a presença de milhares de populares para saudar o general-presidente. Além da presença de operários garantida pelas indústrias locais, também foi assegurado pelas escolas, um grande contingente de estudantes que agitavam bandeirinhas na chegada do general a catedral. Na programação oficial constava um culto ecumênico na catedral do bispado e uma grande solenidade cívica na Fundição Tupy, envolvendo a população da cidade (FREIRE, 2015).

\section{Figura 1 - Ernesto Geisel cumprimenta estudantes na chegada à catedral de Joinville}

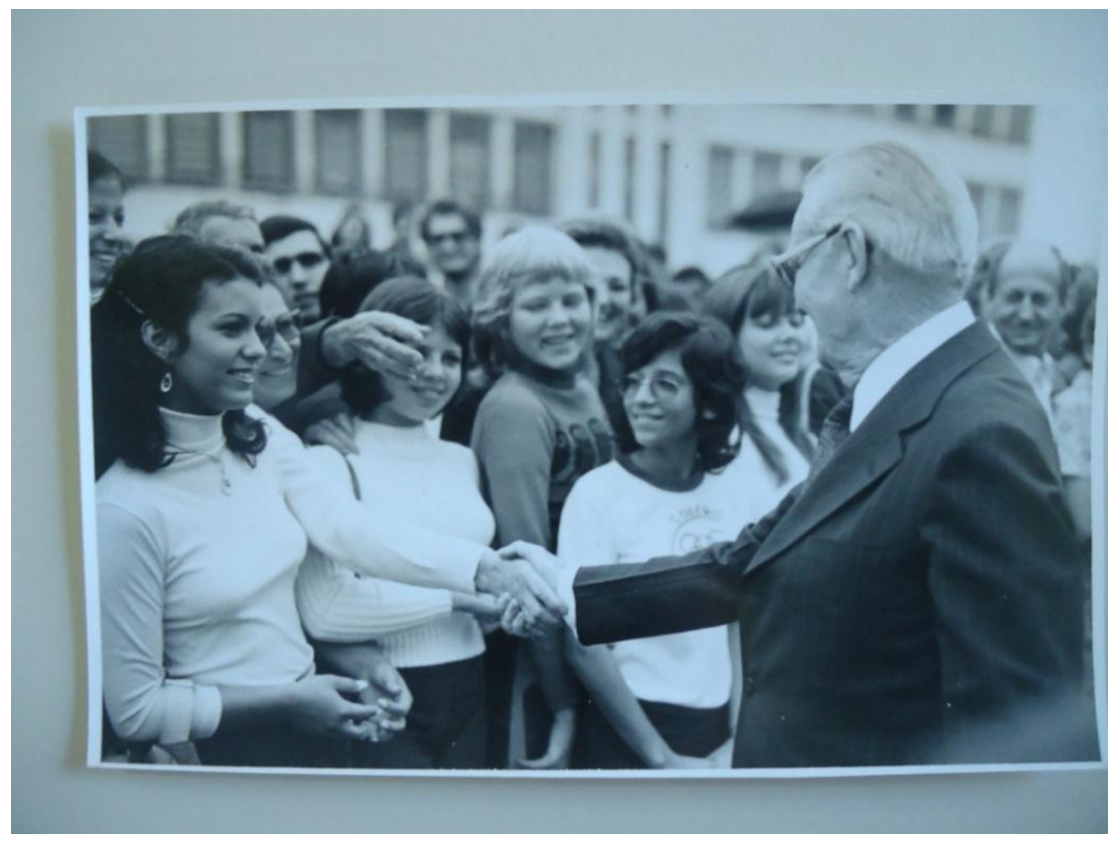

Fonte: Acervo Fotográfico do Arquivo Histórico de Joinville (1975)

Geisel conhecido por sua postura reservada e personalidade retraída (GASPARI, 2016, p. 110) portou-se à vontade, cumprimentou estudantes, conversou em reservado com dois operários da Tupy perante as lentes dos fotógrafos, quebrou o protocolo em diversas situações, ressaltou a imprensa local. A hospedagem do general na residência 
do industrial Dieter Schmidt é um gesto que emoldura a conotação de familiaridade com o "espírito da cidade".

Dias após a visita daquele $1^{\circ}$ de maio, a Petrobrás batizou o maior petroleiro até então construído no país, com o nome da cidade (TERNES, 2010). O "Joinville" foi o primeiro passo do Programa de Construção Naval de 1974, cuja aspiração era "situar o Brasil entre os "maiores construtores navais do mundo" (FICO, 1997, p. 82). A cidade era o símbolo de um Brasil grande que avança pelo trabalho e a ausência de conflito.

O fascínio que a cidade exercia entre setores militares vinha sendo reiterado por autoridades do regime que a visitava. Jarbas Passarinho, Ministro do Trabalho e Previdência no governo Costa e Silva, quando esteve em 1968 em Joinville ressaltou:

\begin{abstract}
Oxalá neste país a mentalidade empresarial que sinto aqui [...], pudesse ser uma regra geral. Oxalá êste (sic) Brasil se inspirasse no exemplo de Joinville para fazer a paz social. [...] pelo exemplo que está a dar para êste Brasil todo, que nós sonhamos exatamente assim: desenvolvido e sem guerra de classes. (ARQUIVO HISTÓRICO DE JOINVILLE, 1968, p. 5). ${ }^{2}$
\end{abstract}

Nos anos que sucederam o golpe, a cidade conseguiu produzir uma interessante inflexão com a utopia autoritária do regime de 1964. Segundo Fico (1997, p. 81-84), essa utopia representou a ressignificação de um imaginário secular de longa duração permeado por uma ideia grandiosa de Brasil em que não raro, era comum falar de "portentoso país" ligado aos seus "grandes destinos", sob a noção de harmonia social. Joinville beneficiou-se imensamente de sua representação de cidade do progresso e da ausência do conflito. Poucas cidades no país pareciam convencer tanto em possuir os distintivos desse Brasil grande.

Outro fator em relação à cidade que merece destaque era o fato de nela estar instalada a maior fundição privada da América Latina: a Fundição Tupy. Os sentidos que presidira a fábrica em termos do que a Escola Superior de Guerra definia como Área de Segurança Nacional e no que possuía de afinidade com o regime era significativa: poderia converter com relativa facilidade sua produção para a indústria bélica, se as circunstâncias impusessem. A presença frequente de militares, sobretudo estagiários da Escola Superior de Guerra que a visitavam, incluindo três generaispresidentes sinaliza para isso.

Além disso, a empresa foi uma das principais beneficiárias de empréstimo estatal. No final do governo Médici, a fábrica recebeu o maior empréstimo da história

\footnotetext{
${ }^{2}$ ARQUIVO HISTÓRICO DE JOINVILLE. Periódicos. Correio da Tupy, Joinville, Jun. 1968, p. 5.
} 
do Banco Nacional de Desenvolvimento Econômico (TERNES, 1988, p. 117-127). Não apenas a Tupy, mas a elite empresarial joinvilense foi uma das mais beneficiadas e os anos de chumbo foram vividos, na cidade, sob o signo dos anos de ouro.

Ademais, o relatório final da Comissão Nacional da Verdade apontou a Fundição Tupy como um caso excepcional de uma empresa privada que cedeu espaço em suas dependências, para o funcionamento de um órgão do regime militar (BRASIL, 2014, p. 74).

\section{A utopia de uma cidade}

Durante anos, antes e depois do golpe, incansáveis esforços foram feitos pelas elites joinvilenses em atribuir a cidade uma identidade fabril, marcada pela presença do colonizador germânico que implantou uma cultura do trabalho, da disciplina e da ordem.

A "Manchester Catarinense", epíteto inventado para Joinville nas décadas de 1960/70, fazia alusão à cidade inglesa de Manchester, referência da revolução industrial, conotação indelével para uma cidade também caracterizada pela paisagem da fumaça das chaminés.

A Manchester, como invenção de cidade pautada no progresso e harmonia social de classes, encontrou ressonância modelar com aqueles que tomaram o poder em 1964 e, durante os anos do regime, tais sentidos políticos presidiram-na. Mesmo após a instauração do processo de democratização, em que novos atores procurariam negar uma identidade monolítica em Joinville, a imagem da Manchester como lugar da ordem e do progresso reivindicou seu peso. Para a cultura empresarial local, as greves que se instauraram na cidade nos anos que sucederam a abertura política, não eram resultado da insatisfação dos trabalhadores, mas de elementos externos transportados de regiões turbulentas do país, sobretudo da região do ABC (FREIRE, 2017).

Para entender como essa representação de Joinville, como cidade da disciplina e da ordem, ganhou forma, seria preciso recuar até a Primeira República e o Estado Novo (COSTA, 1996), com a projeção nacional do empresário Hans Dieter Schmidt, quando a cidade ganhou foros de marketing em outros centros do Brasil: 
O patrão e o empregado não se hostilizam, antes se reúnem em prol das mesmas causas; as greves, tão comuns em outros lugares, ali não existem [...]. Em Joinville, principalmente, apesar de suas 500 indústrias, apesar da enorme concentração de operários, o elemento comunista não obtém êxito, as igrejas se entendem e respeitam, as classes sociais não se distinguem, o trabalho e o senso de responsabilidade confortam e animam dirigentes e dirigidos. Bem quisera eu houvesse em todas as cidades do Brasil aquele espírito pioneiro de Joinville. (ARQUIVO HISTÓRICO DE JOINVILLE, 1963 , p. $4-5)^{3}$.

Há no discurso do industrial a ideia de plasmar uma imagem de cidade marcada pela ausência de antagonismo e conflito social. Tal representação, ao que parece, encontrava ressonância nacional em pessoas que a visitavam. $\mathrm{O}$ discurso do deputado federal Lourival Batista (UDN), no Congresso Nacional em Brasília, em dezembro de 1963, é ilustrativo:

\begin{abstract}
Tive, na semana passada, a agradável surpresa de conhecer um dos maiores centros de trabalho deste País, qual seja a cidade de Joinville, em Santa Catarina. [...] Desde a chegada, pude constatar o clima que respira seu povo. Ali não medram os germes das ideologias espúrias, não fincam o pé os adversários da ordem. Com centenas de fábricas, Joinville desconhece a capacidade destruidora das falsas lideranças sindicais, não se registra movimentos grevistas adrede obtidos para reivindicações alienadas de seus reais interesses. Vi em Joinville uma comunidade operária tranqüila, senhora de suas responsabilidades, distanciada da politicagem subdesenvolvida dos comandos gerais. Ali, um trabalhador sabe quais são as suas obrigações, entende quais são os seus direitos e o parque industrial caminha sem tropeços. [...] Por isto Joinville se assemelha a uma colméia, respirando trabalho e ação por todos os cantos. [...] Desta Tribuna quero louvar, de público, o espírito empreendedor do capital e do trabalho em um dos maiores centros fabris do interior brasileiro! (ARQUIVO HISTÓRICO DE JOINVILLE, 1963, p. 23 - grifos no original). ${ }^{4}$
\end{abstract}

Em que pese o deputado Lourival Batista ser um representante da UDN, e esta possuir significativo peso na política local da cidade, não parecem despropositais os destaques em negrito que a redação do Correio da Tupy introduziu no texto do discurso do parlamentar, pois ecoa a utopia de um centro urbano que deveria funcionar como uma colmeia. Interessante é notar como a metáfora vinha sendo empregada nos discursos locais, antes e depois de 1964, como uma estratégia discursiva para - a produção de sentidos. A colmeia não é o espaço do conflito, mas o lugar onde tudo funciona dentro da mais perfeita ordem.

A ideia de colmeia bebe na matriz de uma cultura política, pensada aqui como um código ou conjunto de referentes difundidos e partilhados no seio de uma tradição

\footnotetext{
${ }^{3}$ ARQUIVO HISTÓRICO DE JOINVILLE. Periódicos. Correio da Tupy, Joinville, jul. 1963, p. 4-5.

${ }^{4}$ ARQUIVO HISTÓRICO DE JOINVILLE. Periódicos. Correio da Tupy, Joinville, dez. 1963, p. 23.
} 
política (BERSTEIN, 1998, p. 350). Um código composto por uma vulgata acessível a um grande número de pessoas como uma leitura comum e normativa da sociedade. Ela nos ensina, mais uma vez, conforme pontua Berstein: "uma concepção da sociedade ideal tal como veem os detentores dessa cultura.” (BERSTEIN, 1998, p. 350).

A cultura política local pautava-se na ausência da negociação social, uma das funções da sociedade democrática. Assim é o estrato de uma cultura política autoritária. Quando uma cultura política é dominante, poderá ela contribuir para moldar a sociedade a qual pertence? Joinville é o lugar onde todos se entendem; onde as igrejas não rivalizam entre si; onde as classes sociais não se distinguem; onde não há lugar para germinar ideologias espúrias; onde o trabalho harmoniza as relações entre dirigentes e dirigidos.

A cidade ideal, inscrita nessa vulgata, procura delimitar o modo como deveria ser percebida, desejada e representada, fundada numa ilusão totalizante. A colmeia é, pois, o véu que encobre a luta por um idílio, alimentado por uma cultura política autoritária, ela é anterior ao golpe de 1964.

Para pensar a natureza do regime de 1964, a noção de cultura política é inestimável. Ver o autoritarismo dos anos do regime, não como mera ruptura com a ordem democrática, que abriu um parêntese em sua história, reestabelecida anos depois (AVRITZER, 1995), mas como uma cultura política preexistente que lhe fazia concessão. A ditadura foi mais que um poder que se impôs verticalmente e que a sociedade nada tinha a ver com o autoritarismo.

\section{Arremates}

De tudo que uma cidade outorga ao olhar que a perscruta, são as respostas que permitem decifrá-la o que melhor de si oferece. E para isso, é necessário interpelá-la com a perspectiva do viajante, sabendo de antemão que a cidade carrega consigo um passado que nem sempre convém à sua memória pública evocá-lo. Tal passado traz consigo não somente respostas, mas renovadas indagações que o torna aberto e inconclusivo aos estratos do tempo.

Uma coisa é certa, Joinville consente enxergar nas relações que manteve com o regime de 1964, afetos e abraços que se encerram. E, a sombra desse passado, continua a incidir em seu presente, afinal, ainda há muitos monumentos à ditadura na cidade. Alguns não mais visíveis como a Escola Municipal de $1^{\circ}$ Grau 31 de Março, e quiçá o 
título de cidadão honorário de Joinville concedido a Médici pelo legislativo. Mas, há monumentos que figuram no cotidiano da cidade como a Praça Marechal Castelo Branco no centro, as escolas Presidente Médici, Presidente Costa e Silva e Presidente Castelo Branco. E o mais visível e notório: o Costa e Silva, nome dado a um bairro feito para operários.

Pouco se fala desse passado da cidade, porque soa desconcertante: há muitas testemunhas vivas que conviveram muito bem com o regime de 1964. Daí haver mais silêncios que vozes. Se quiser decifrá-la, o viajante terá que atentar para os silêncios que permeiam também a cidade. Tanto melhor se compreenderá uma sociedade, considerando aquilo que silencia por lapsos de "esquecimentos", que aquilo que comemora e faz questão de lembrar (CANDAU, 2014, p. 150).

O inventário de afetos de uma cidade com o regime de 1964, de longe será conveniente produzi-lo, sobretudo em associá-la a um regime que viria tornar-se odioso. E, de outro lado, a atitude social de virar a página por si só, já depõe contra o silêncio daqueles que fizeram parte das redes de sustentação do regime e continuam aí. 


\section{REFERÊNCIAS}

\section{Fontes primárias}

ARQUIVO HISTÓRICO DE JOINVILLE. Jornais. Geisel inaugura o Centro Social Urbano no Itaum. A Notícia, $2^{\circ}$ Caderno, Joinville, 20 out. 1978, p. 1.

ARQUIVO HISTÓRICO DE JOINVILLE. Fotografias. Presidentes da República em Joinville.

ARQUIVO HISTÓRICO DE JOINVILLE. Periódicos. Correio da Tupy, Joinville, jul. 1963, p. 4-5.

ARQUIVO HISTÓRICO DE JOINVILlE. Periódicos. Correio da Tupy, Joinville, Dez. 1963, p. 23.

ARQUIVO HISTÓRICO DE JOINVILLE. Periódicos. Correio da Tupy, Joinville, Jun. 1968, p. 5.

\section{Fontes secundárias}

AVRITZER, Leonardo. Cultura política, atores sociais e democratização: uma crítica às teorias da transição para a democracia. Revista Brasileira de Ciências Sociais, São Paulo, v. 10, n. 28, 1995.

BERSTEIN, Serge. A Cultura Política. In: RIOUX, Jean-Pierre; SIRINELLI, JeanFrançois (Org.). Para uma História Cultural. Lisboa: Estampa, 1998.

BRASIL. Relatório: Comissão Nacional da Verdade. vol. II. Brasília: CNV, 2014.

CALVINO, Ítalo. As cidades invisíveis. São Paulo: Companhia das letras, 1990.

CANDAU, Joël. Memória e identidade. São Paulo: Contexto, 2014.

CORRÊA, Roseana Maria; ROSA, Terezinha Fernandes (Coord.). História dos bairros de Joinville (Arquivo Histórico de Joinville). Joinville: Seigraph, 1992.

COSTA, Iara Andrade Costa. A cidade da ordem: tensões sociais e controle (Joinville 1917-1943). 1996. Dissertação (Mestrado em História) - Universidade Federal do Paraná, Programa de Pós-Graduação de História, Curitiba, 1996.

FICO, Carlos. Reinventando o otimismo: ditadura, propaganda e imaginário social no Brasil. Rio de Janeiro: FGV, 1997.

FREIRE, Izaias de Souza. Ecos de democratização: uma análise das vozes do processo de transição do regime militar em Joinville. 2015. Dissertação (Mestrado em História) Universidade do Estado de Santa Catarina, Programa de Pós-graduação em História, Joinville, 2015. 
FREIRE, Izaias de Souza. Cultura política autoritária e democratização: a Manchester à sombra da ditadura. Curitiba: Editora Prismas, 2017.

GASPARI, Elio. A Ditadura Acabada. Rio de Janeiro: Editora Intrínsica Ltda, 2016.

GINZBURG, Carlo. "Sinais: raízes de um paradigma indiciário". In: Mitos, emblemas, sinais: Morfologia e História. 1ª reimpressão. São Paulo: Companhia das Letras, 1990.

TERNES, Apolinário. A Estratégia da Confiança. Joinville: S. ed., 1988.

TERNES, Apolinário. Tempos modernos: a presença de italianos em Joinville, 19732008. Joinville: Editora Univille, 2010.

RICOEUR, Paul. A memória, a história, o esquecimento. Campinas: Editora Unicamp, 2007. 